\title{
Assessment of Respiratory Muscle Strength in Obese Young Adults
}

\author{
Uma B.V. ${ }^{1}$, Pramod $^{2}$, Ragavendra ${ }^{2}$, K.N. Maruthy ${ }^{3}$ \\ ${ }^{1}$ Associate Professor, ${ }^{2}$ MBBS Student, ${ }^{3}$ Professor, Department Of Physiology, Narayana Medical College, Nellore
}

\begin{abstract}
Introduction: Obesity is also called as disease of 21 st century. Obesity is defined by WHO as "A Medical condition in which excess body fat has accumulated to the extent that it may have adverse effects on health consequences". The BMI is an attempt to quantify the amount of fatty mass in an individual.

Various complications of obesity on respiratory functions were studied by many researchers. Few studies are conducted in India on obesity to assess the respiratory muscle strength, obtained controversial findings.

Objectives: To assess the respiratory muscle strength in obese and non obese young adults.

Material and Method: After getting clearance from ethics committee, experiments were performed as per study protocol in the Department of Physiology, Narayana medical College, Nellore.

Based on BMI values subjects were classified as borderline obese (BMI more than 25) and non obese groups (34 in each group, age group between 18 to $25 \mathrm{yrs}$ ) .

Anthropometric measures were taken along with the total body fat $\%$ using Bio-impedance instrument.

PIP \& PEP were recorded by using digital manometer device capable of measuring both negative and positive pressures along withthe mouth piece, which was in house built and calibrated by using mercury manometer.

Results: In our study, PIP \& PEP of non obese is $111.7 \pm 17.3 \mathrm{mmHg} \& 61.8 \pm 12.5 \mathrm{mmHg}$ respectively. Similarly PIP \& PEP of borderline obese was found to be $121.2 \pm 17.3 \mathrm{mmHg} \& 62.3 \pm 12.2 \mathrm{mmHg}$ respectively. There is an increase in PIP values which is statistically significant in borderline obese group. Similar findings were observed in other studies.

Conclusion: We conclude that, PIP increased in borderline obese subjects but not in PEP. According to previous studies, obesity enhances the strength of respiratory muscles. This continuous overburden adapts the respiratory muscles to generate more pressure during respiration. This we could observe only in inspiratory group of muscles in borderline obese subjects.
\end{abstract}

Keywords: Peak Inspiratory Pressure (PIP), Peak Expiratory Pressure (PEP), Hand grip strength.

\section{Introduction}

\section{Corresponding Author:}

Dr. Uma. B.V.

W/O Dr. N. Hemanth Kumar, Flat No. 305, Balaji

Sunshine Apartment, Aditya Nagar, Near Childrens

Park, Nellore -524003 A.P.

Mobile: 9441685841

e-mail: umahemi@gmail.com
The lifestyle of society is changing from agricultural life to industrial life, where sedentary works are more. Along with that eating habits, frequency $\&$ fat content of food has increased which will increases the prevalence of obesity.

So obesity is a fast growing global health, social and economical problem. It is also called as disease 
of 21 st century. According to WHO obesity is defined as "A Medical condition in which excess body fat has accumulated to the extent that it may have adverse effects on health consequences". The BMI is an attempt to quantify the amount of fatty mass in an individual

So change in life style and lack of physical activity are two main factors of obesity which impairs quality of life and number of obesity cases may still increase in 21 st century ${ }^{1}$.

Respiratory muscle strength (RMS) is responsible for respiratory mechanics. Expansion during inspiration $\&$ recoiling during expiration is totally depends on the respiratory muscle strength ${ }^{1}$.

Obesity is important risk factor for diabetes, hypertension, atherosclerosis, cancer etc. It also causes respiratory muscle strength disturbances. It may be due to an increase in tensile strength caused by excessive adipose tissue in the thoracic cage and abdomen ${ }^{2}$. So assessment of respiratory muscle strength in the form of pressure is a simple, rapid, inexpensive, accurate, portable $\&$ ideal for bedside patients .

Aim: To assess the respiratory muscle strength in obese young adults

\section{Material and Method}

After getting clearance from ethics committee, informed consent was taken from all the participants and different parameters including peak inspiratory and expiratory pressures were recorded as per study protocol. Data collection was done in the Department of Physiology, Narayana Medical College, Nellore.

Participants: Based on BMI values subjects were divided into 2 groups. Borderline obese and non obese. (34 in each group).

Test Group: 34 borderline obese (BMI $<25$ - 29>) aged between $18-25 \mathrm{yrs}$

Control Group: 34 non obese (BMI $<25)$, aged between $18-25 y r s$

\section{Inclusion Criteria:}

- $\quad$ Subject aged between 18 - 25 yrs

- No H/O DM \& Hypertension

- No H/O medication

\section{Exclusion Criteria:}

- $\quad$ Subject aged $<18$ or $>25$ yrs

- H/O DM \& Hypertension

- $\mathrm{H} / \mathrm{O}$ medication

\section{Parameters:}

- Height \& Weight were measured by using Stadiometer \& Digital weighing balance.

- Total body fat $\%$ was measured by using body fat analyser based on Bio-impedance principle.

- Body Mass Index was calculated by formula (Weight in Kgs/Height in meter square).

- Peak Inspiratory \& Expiratory Pressure were recorded by digital PI \& PE pressure monitoring device which was a custom built, calibrated by using mercury manometer.

Methodolgy: It's a simple age \& height matched case control study. Subjects were asked to come to the Laboratory between 9 am to 11 ambecause PI \& EP shows diurnal variations i.e it increases in morning after 10am. After 10 minutes rest Height \& Weight were recorded to calculate BMI. Subjects were asked to exhale air completely (with out device), nose clip was applied \& instructed to inspire through the mouthpiece of the device to get PIP.Subjects were asked to take deep breath (with out device), nose clip was applied \& instructed to exhale into the mouthpiece of the device to get $\mathrm{PEP}^{3}$.

Three readings were taken with a gap of one minute rest $\&$ highest value is selected for analysis.

\section{Results}

Table 1: General characteristics

\begin{tabular}{|l|c|c|}
\hline Parameters & $\begin{array}{c}\text { Non Obese } \\
\text { Mean } \pm \text { SD }\end{array}$ & $\begin{array}{c}\text { Border Line Obese } \\
\text { Mean } \pm \text { SD }\end{array}$ \\
\hline Age $(\mathrm{yrs})$ & $19.2 \pm 1.0$ & $19.3 \pm 1.3$ \\
\hline Height $(\mathrm{cms})$ & $165.7 \pm 6.8$ & $166.7 \pm 7.2$ \\
\hline Weight $(\mathrm{Kgs})$ & $64.4 \pm 6.7$ & $77.2 \pm 7.01$ \\
\hline BMI & $23.3 \pm 2.3$ & $27.9 \pm 1.7$ \\
\hline
\end{tabular}

Table 2: Respiratory pressures

\begin{tabular}{|l|c|c|}
\hline Parameters & $\begin{array}{c}\text { Non Obese } \\
\text { Mean } \pm \text { SD }\end{array}$ & $\begin{array}{c}\text { Borderline Obese } \\
\text { Mean } \pm \text { SD }\end{array}$ \\
\hline PIP $(\mathrm{mmHg})$ & $111.7 \pm 17.3$ & $121.2 \pm 17.3$ \\
\hline PEP $(\mathrm{mmHg})$ & $61.8 \pm 12.5$ & $62.3 \pm 12.2$ \\
\hline
\end{tabular}


In our Study: There was an increase in PIP values which is statistically significant $(\mathrm{p}=0.027)$ in borderline obese group.

\section{Discussion}

Obesity is a risk factor for various diseases, including respiratory system. It mainly decreases lung compliance. Obesity increases respiratory muscle strength because muscles have to work constantly against decreased lung compliance and high airway resistance, due to fat deposition which requires more force for mechanism of ventilation. Increase in respiratory muscle strength may be due to adaptation to the chronic overload which could generate more pressures ${ }^{2}$. Pressure generated by respiratory muscles is measured as peak inspiratory \& expiratory pressures . The respiratory muscles are as vital as the heart and on long term muscle strength decreases and leads to other complications. So assessment of respiratory muscle strength in the form of pressure is a simple, rapid, inexpensive, accurate, portable $\&$ ideal for bedside patients .

\section{Conclusion}

Adolescent obesity can be prevented by takling childhood obesity because it is very difficult to reduce the weight once it is gained by young individuals of present generation with modern life style .

So we conclude that,

- Childhood obesity can be controlled by awareness programs such as school health programs and regulation of junk food marketing.

- Recording of PIP \& PEP in obesity might be helpful in early diagnosis and prevention of respiratory complications.
- In general, obesity can be prevented if active measures are taken to reduce weight by change in lifestyle \& food habits.

Ethical clearance taken from the committee.

\section{Acknowledgement: Nil}

Conflict of Interest: Nil

Source of Funding: Self

\section{References}

1. Shinde B.V.et al "The Impact of Obesity on Respiratory Muscle Strength in Adults" International Journal of Contemporary Medical Research ISSN (Online): 2393-915X; (Print) : 2454-7379, September 2017, ICV: 77.83, Volume 4, Issue 9.

2. M. Pazzianotto-Forti et al, "Behavior of respiratory muscle strength in morbidly obese women by using different predictive equations". ISSN 1413-3555 (Original article., Nov./Dec. 2012, Volume- 16, Issue - 6, P. no - 479-86.

3. K. N. Maruthy and Mario Vaz "The development and validation of a digital peak respiratory pressure monitor and its characteristics in healthy human subjects" Department of Physiology, ST. John's Medical College, Indian J Physiol Pharmacol 1999; 43 (2): 186-192 .

4. E.G. Furman et al, " Lung Function and Respiratory Muscle Strength in Obese in Children”, Pediatričeskaa Farmakologia, Volume 12, Number 2, 2015, P . no - 143-147(5). 